\title{
The Problem of the Origin of Species as it appeared to Darwin in 1859 and as it appears to us To-day. ${ }^{1}$
}

\author{
By Prof. Henry Fatrfield Osborn, For. Mem. R.S.
}

The first of these objects, that is, the establishment of a belief in descent with modification, was always held by my father to be the more important of the two; for I once heard him say, if a recollection of about fifty years' standing may be trusted, that " after all, evolution is the great thing, not natural selection."-LEONARD DARWIN, "Organic Evolution," pp. I, 2.

NEARLY one hundred years ago Charles Darwin began to collect facts for " The Origin of Species," his immortal work, which was cautiously withheld from publication until 1859 . There still prevailed the zoology of Linnæus and Buffon and the palæontology of Cuvier. In Lesson's "Mammalogie" (1827) the number of mammalian species is exactly $\mathrm{x} 24$, as compared with the $13,45^{\circ}$ species and subspecies of mammals known at the end of the year 1925 . Birds increased from 3600 to 23,939 ; reptiles and amphibians from 543 to 9000 ; fishes from 3500 to 20,000 . Darwin's species stood apart like isolated mountain peaks, whereas to-day living species and subspecies are often comparable to mountain chains composed of lesser peaks completely connected by ridges known as intergradations. It is not the number of species and subspecies which is significant, but the facts as to habit and habitat which are recorded with them. Similarly, it is not the number of fossil species now known as compared with those of Darwin's time, but the linkage of families, genera, species, subspecies, and even of 'ascending' and 'descending mutations' reaching back over hundreds of thousands, if not millions, of years.

This twenty- to one hundred-fold disparity in our knowledge simply intensifies our admiration for the courage of Darwin in boldly substituting a natural for a supernatural conception of the origin of species. It is true that Darwin's most influential authority was not the current zoology and palæontology of his day but Nature itself, whereby even in 1859 he absolutely established the Law of Evolution, as well as the directing and standardising principle of Natural Selection. It is, however, not this broader aspect of evolution, but the more concrete problem of the modes and causes of the origin of species which we are considering to-day.

Let us re-examine these causes in the light thrown by naturalists and observers on the invertebrates and vertebrates as distributed over the great continents of Europe and Asia, of North and South America, of Australia, considered not alone with their present boundaries but also with their former land connexions secured by elevation to the hundred fathom line. In this connexion I present a new zoogeographic and palæogeographic map of the world, prepared with the aid of Bartholomew of Edinburgh. We shall see that the results of zoological and palæontological research are entirely harmonious and concordant, but that zoology,

${ }^{2}$ Read before Section D (Zoology) of the British Association, at the Oxford meeting, August 5,1926 . This is the fourth of a series of papers on the origin of species, the first having appeared in NATURE, June I3 and 20,1925 , under the title, "The Origin of Species as Revealed by Palæontology."

$$
\text { NO. 2964, VOL. II } 8]
$$

while clearly teaching certain principles of the origin of species, leaves blank many gaps which are completely filled by palæontology.

Thus these two branches of biology are complementary in demonstrating that, through observations after the very naturalistic manner of Darwin in the voyage of the Beagle and through the very: Lyell-Darwin methods by which the natural origin of species was originally discovered, the problem of the origin of species has entirely changed in the last hundred years. In fact, were the great naturalist living to-day, he would be foremost in modifying his own opinions, speculations and theories.

Greatly enhancing the value of the recent work of our field naturalists is the fact that the results reached in fishes, amphibians, reptiles, birds and mammals were recorded entirely independently of each other. Where the conclusions reached are harmonious or concordant they have the convincing value of entirely independent testimony. Also, these results are doubly valuable because they are for the most part assembled without biological purpose or intent, not to prove or to disprove any particular theory, but recorded simply as actual observations.

This is generally true of all field naturalists, who are more concerned about Nature than about the interpretation of Nature. The interpretations upon which our field naturalists do venture, such as the ' direct action of environment,' and 'Lamarckian inheritance,' are often lacking in real biological analysis. For such analysis, therefore, we must allude to five biological principles which have developed from laboratory experiments, and the generalisations growing out of them, beginning chiefly in the year 1880. These are as follows:

(I) Weismann's sharp distinction of the germ-plasm from the body plasm, from which follows the equally sharp distinction between truly germinal specific characters and bodily modifications by environment or habit; (2) the experimental failure of the inheritance effects of adaptive habit, known as Lamarckism; (3) the apparent failure of the environment to modify immediately the germ-plasm in creating adaptive specific characters; (4) the sharp limitations of the originative powers of Natural Selection as conceived by Darwin; (5) the sharp distinction between the continuous and discontinuous (or mutational) origin of specific characters.

In fact, the outstanding speculations of Darwin's and Herbert Spencer's time as to the causation of the origin of species have been pared down by laboratory analysis to a mere yestige of their former selves, and the overweening confidence of one school of causation after another has been displaced by diffidence, doubt, or even agnosticism, as expressed in the final address of William Bateson, whose recent death we lament at this meeting. To sum up, intensive laboratory and experimental research has added vastly to our knowledge of the functions of animals and of the heredity mechanism but has greatly increased the difficulcies 
inherent in the problem of the origin of species. It is the modes and the causes of the onward progressive movement of the germ-plasm resulting in the consecutive origin of new adaptive specific forms which are rendered still more mysterious by the negative results of laboratory research.

\section{Distinction between Speciation and Mutation.}

So far as the modes of the origin of species are concerned, these negative results of the laboratory are more than offset by the positive results obtained by our field naturalists and explorers who are independently discovering a considerable number of species-in-themaking at the present time. In other words, we now understand the contemporary origin of species after modes and under conditions wholly unknown to Darwin in I859. Geographic isolation, to which Darwin's attention was first directed by Wagner, with all the incidental influences of physical or chemical change, of enforced change of habit, of competition with a new life environment, perhaps of stimulus to the germinal energies themselves, seems to constitute the chief complex of causes in the origin of new species; this complex is summed up in the principles which Osborn terms tetraplasy and tetrakinesis. An extreme phase of isolation is insulation, where species are scattered among a number of islands. A like isolating mode among fishes is seen in the complete separation of rivers and streams formerly connected. In this complex of four coefficient causes, all involving energy, the specific germinal substance itself undergoes change, extremely slow but continuous, so that a new stage is very gradually reached, formerly known as a ' geographic variation' but now known as a 'subspecies.' Between subspecies living in islands and separated rivers there are naturally no intergrades or intermediate stages, but in a number of independent examples among fishes, amphibians, reptiles, birds and mammals, true intergradation has been observed linking one subspecific form with another in a continuous germinal life-chain. Such survival of intergrades may be instanced as proof of complete continuity between subspecies and, consequently, between species.

This appears to be the normal and natural mode of urigin of the greater number of specific forms as obs?rved in zoology; such mode has been termed 'speciation' by recent British and American authors. In exactly the same field of observation and by the same obsirvers, apparently as an abnormal mode due to some irregular influence on the specific germ-plasm, is seen the discontinuous or sudden origin of new characters, ranked by some observers as specific, after the manner termed 'chance variation' by Darwin and 'mutation' by De Vries. Mutation thus appears to be a real phenomenon, but a relatively rare one; such mutational origins need to be protected by geographic or climatic isolation from interbreeding with normal species.

Thus speciation through continuity stands in contrast with mutation through discontinuity. There is no question as to germinal change in mutations, but may the same be said of subspecies? In answer to this doubt it has recently been shown by experiment (Sumner 1924) that many, if not all subspecific characters are stable under changed conditions of environ- ment. Consequently, while under suspicion as to reality, often vexatious and unconvincing, and always annoying to the systematist, well-authenticated subspecies are of priceless value to the biologist who seeks to ascertain the conditions under which new species arise. It proves that many 'geographic variations' and 'subspecies' are really germinal transitions, intermediates and intergradations from 'species' to 'species' of the higher kind known to Darwin.

The above is a summary of principles gathered from a very large number of independent observers whose names will be fully recorded with the titles of their papers in the complete series of notes on which the present paper is based. Outstanding names are those of Adams in the gastropods, Jordan, Berg and Regan in the fishes, G. A. Boulenger in the amphibians, E. G. Boulenger in the reptiles, Chapman and Griscom in the birds, Osgood and Sumner in the mammals. The whole list of observers in the vertebrates alone comprises more than a hundred names. For the annotation of this extensive literature I am indebted to members of the corps of zoologists of the American and British Museums and of the Zoological Society of London. ${ }^{2}$

\section{Examples of Geographic Isolation and SPECIATION.}

It appears that speciation arises only where one or all of the energy coefficients of Osborn is changed. In amphibia especially, geographic isolation does not invariably result in the origin of new species, because all the conditions of the new habitat may be identical with those of the old. A most striking example of complete intergradation between 'species' is that of the molluscan genus Io of the Tennessee River, which now presents all the living intergrades between the smooth and the spinose forms as we pass downstream. In fishes, skeletal intergrades are observed as we pass from northern to southern waters (Berg) or from a colder to warmer marine habitats; these intergrades consist in the number of vertebræ, of fin rays and of scales, and in body form and colour, and Berg concludes that all the individuals of certain geographic areas simultaneously produce similar new specific characters.

Among amphibians the entire region around the Mediterranean affords G. A. Boulenger a series of subspecies of the edible frog, Rana esculenta, more or less connected by intergrading forms. Among reptiles E. G. Boulenger observes the speciation of the skink, Chalcides ocellatus, a species which, like the edible frog, surrounds the Mediterranean, in which the difference between two isolated subspecific forms is so great that were it not for the wonderfully complete manner in which they are connected they could not be denied full specific rank. As among fishes, intergradations are observed in all the skeletal characters, as well as in the colouring and the scales. Completely supporting these observations are those of many of the recent herpetologists who conservatively use the word 'variety' where other authors use the word 'subspecies,' who imply that intergradations occur wherever a sufficiently large number of specimens are examined. Chapman, with extensive collections of South American birds at his command, records exactly similar results :

2 These data will be published in full in a sequel to the present paper, in the American Naturalist, No. 5 , in the series on the origin of species.

$$
\text { No. 2964, VOL. I I } 8 \text { ] }
$$


The ornithologist finds large forms occupying colder areas, dark ones humid areas, and pale ones arid areas; and as the [environmental] conditions which obviously produce these variations in size and colour merge one with the other, so do the [specific and subspecific] forms themselves intergrade. That these variations are inherent [i.e. germinal, constitutional, hereditary] and not merely the temporary impress of physical environment on the individual, is apparently shown by the fact that they are often as well marked in the nestling as in the adult.

Chapman also observes a distinct case of 'mutation' within the genus Buarremon in the presence of a black pectoral feather-band, which is established as a specific character by isolation or geographic discontinuity. Like the single case with black dorsal band observed within the genus Troglodytes, the mutation does not intergrade and is thus recognised as of discontinuous or mutational origin. Stresemann finds partial melanism as well as albinism arising as not infrequent mutational characters, but fails to show that these are adaptive. Chapman and Griscom in their North and South American field work distinguish clearly between intergrading and non-intergrading kinds of birds. In a collection of $I_{500}$ specimens of the house wren, Troglodytes, these observers have noted a considerable number of cases of complete intergradation between subspecies, and those familiar with the marked physiography of South America, with $(a)$ its cold and arid Pacific coastal belt, $(b)$ its Andean Mountain chain subdivided by Chapman into numerous vertical lifezones each clearly demarcated until we reach the boreal summits, (c) its vast Amazonian forest plain, $(d)$ its pampas and plains of the south-east, and $(e)$ humid forests bordering the Straits, may anticipate wide speciation in other forms of animal life in this continent. It is noteworthy that these observers have discovered in Troglodytes only one example of mutation in the sense of De Vries. It cannot be questioned that isolation is the most important factor in the speciation of birds, especially in its extreme form of insulation. As an example of wide isolation without speciation, the house wren of Florida, T. adon adon, exhibits the same characters as those of Tierra del Fuego, but in the intermediate regions another species, T. musculus, exhibits a large amount of subspeciation and several complete intergradations.

Among mammals the great transverse geographic range from Scotland across Eurasia and North America to New Brunswick, Canada, of three species of the deer family, affords a striking example of geographic speciation; the stag (Cervus) yields twenty-three species and subspecies; the moose (Alces) yields eight subspecies; the reindeer (Rangifer) yields twenty-one subspecies. This is in wide contrast to the knowledge of Darwin (I837-I859), to whom were known only two species of stag, one species of moose, and one species of reindeer. Far more significant, however, are the observations of Osgood and Sumner on the deer-mice of the genus Peromyscus, which range through the temperate region of North America to the Pacific coast. From a collection of 30,000 specimens Osgood finds that a subspecies is characteristic of every distinct climatic region and sub-region. These subspecies listed by Merriam and Osgood have been accepted with great reluctance, especially by naturalists unfamiliar with the excessively sharp geographic and climatic barriers of the western United States. Our hesitation to accept these subspecies as of real germinal or genetic value has been entirely removed by the persistent observations and experiments of the biologist Sumner, largely in the identical collecting grounds of Osgood, and we must welcome these combined observations and experiments as the most convincing demonstration of the principle of speciation continuity thus far afforded. Between at least six of these subspecies complete intergradations occur. Classification becomes like dividing the lines of the spectrum. After eight years of transfer from an arid to a humid environment, or vice versa, these subspecies retain their original characters. Even profound change of environment does not yield a new subspecific form, nor are changes of habit inherited in eight years of experiment.

(I) The summary of eight years' experiment proves the comparative stability of subspecies of the Deermice (Peromyscus) under very marked new environmental phyșical conditions. (2) Merriam-Osgood subspecies are proved to be stable under changed conditions of environment, by transplantation experiments; i.e. a desert subspecies, P. $m$. sonoriensis, reared for eight years in a humid environment, is entirely unmodified in the direction of the humid subspecies P. m. gambeli. (3) This doubly proves (a) that characters of the desert $P . m$. sonoriensis are germinal, not environmental; (b) that humid environment makes no modification whatever toward increased depth of colour in eight years and in seven to twelve generations. (4) Similar results from transplantation of $P$. m. rubidus and $P$. m. sonoriensis are obtained: reared in an entirely new environment, they do not converge toward each other but toward local humid species P. m. gambeli.

\section{Speciation a Secular Phenomenon.}

Whereas an inheritable mutation may be produced by a single experiment, 40,000 years, the lapse of time since the last glaciation, is a moderate estimate of the time required to produce a subspecies. In the case of all the genera cited above--Cervus, Alces, Rangifer, Rana, Chalcides, Troglodytes, Peromyscus-we. are observing subspecies arising in a region which was profoundly affected by the fourth glaciation with its pluvial climate, a region in which new subspecies have arisen pari passu with the modern demarcations of habitat and of habit. That speciation is an incredibly slow process is attested by the case of the newly discovered Pliohippus of Leidy, which early in Pliocene time assumed all the characters of the modern Equus. The entire speciation process of plants and animals has been going on perhaps for a thousand million years, as estimated on purely physical grounds, and in a recent conversation with Sir Ernest Rutherford it was agreed that another thousand years of research may be required for an understanding of the highly complex physico-chemical basis of life.

\section{Concordant Observations in Zoology and PalæONTOLOGY.}

As distinguished from the speciation observed in zoology, in palæontology we deal with secular speciation, in which, quoting from the first of Osborn's series of 
papers on the origin of species, we observe the adaptive action and reaction of the heredity germ over long periods of time. We also observe the secular action of natural selection (Darwin's selection factor), the secular direct reaction to environment (Buffon's factor), the secular adaptive action of habit (Lamarck's factor), the secular adaptive reaction to the living environment (Darwin's factor). We sharply separate Darwin's factor of selection, which has no energy content, from the above four energetic forces of evolution, namely, heredity, physical environment, living environment, and individual development or ontogeny. This is the principle of tetraplasy and tetrakinesis.

This momentary lapse into speculative as distinguished from purely observational consideration of the problem of the origin of species may clarify the transition from zoology to palæontology.

In palæontology an entirely new series of principles is discovered in speciation which are quite beyond the eye of the zoologist. Chief among thesenew principles is that dimly perceived by Darwin in the words 'analogous variation'; it is that of germinal or evolutionary trend in a definite direction, the 'mutations richtung' of Neumayr. Out of this springs Osborn's principle of rectigradation observed in the rise of adaptive characters from the germ-plasm, that is, new specific characters which pass continuously from the most rudimentary and inefficient into the most efficient and highly developed stages. It may be a matter of interest to members of the British Association to recall that this principle was presented to the Association in 1889 by the present speaker. Through unbroken observation during the intervening thirty-seven years this rectigradation principle has been confirmed in four great orders of hoofed mammals, namely, the horses, the rhinoceroses, the titanotheres, and the proboscideans. Research on the two latter groups fills two great monographs aggregating nearly a million words and covering, in the case of the Proboscidea, the analysis of the mode of origin of more than 350 species and, in the case of the titanotheres, the chief stages of specific development extending from Lower Eocene through Lower Oligocene time, when these animals suddenly disappear.

An epitome of these observations is presented in three diagrams in which the three outstanding principles discovered in palæontology are observed: First, the unbroken continuity of speciation, which becomes absolute as the gaps are filled by discovery. Second, the constitutional predisposition to speciate in certain predetermined directions which must be inherent in the germ-plasm of ancestral forms. Third, that these constitutional predispositions are not released except through adaptive reaction to new conditions of life; they are not, therefore, of the nature of inherent perfecting tendency, but, rather, of the nature of a potentiality to appear when the need for them arises. For example; the rhinoceroses have the potentiality of developing two horns, an anterior horn on the nasal bone and a posterior horn on the frontal bone. But in the fourteen branches into which this great subfamily subdivides in its migrations to all parts of the earth, this double potentiality is seldom availed of, sometimes not availed of at all.

\section{Conclusions.}

We seem to have reached an entirely new era in research on the problem of the origin of species, marked by the decline and death of speculations and theories advanced upon the very limited knowledge of the first half of the nineteenth century. Through zoology and palæontology we have reached a solution of the least difficult half of the problem with which Charles Darwin was confronted: we know the modes by which subspecies and species originate; in fact, there is little more on this point to be known. But this very knowledge renders the problem of causes infinitely more difficult than it appeared to Darwin. The causes of 'variation,' to use the term he employed for the evolutionary process, lie in the way before us. They may be resolved or they may prove to be beyond human solution. We must resolutely face these alternatives, and in the meantime continue our synthesis over every field of biologic research.

\section{The Geographical Distribution of Magnetic Observatories.}

\section{By Dr. C. Chree, F.R.S.}

$\mathrm{T}$ HE provision for observational work in terrestrial magnetism is different in kind in different countries, and in some countries-Great Britain, for example-- the provision made is of more than one kind. The object in view may be purely utilitarian, or purely scientific, or partly both. Originally the provision of information necessary for the use of the compass was the one utilitarian object generally recognised. To secure this object to the best advantage, the natural course is to make a single department responsible for the running of magnetic observatories, the taking of field observations and the preparation of charts. Thus, in the United States the Coast and Geodetic Survey controls the whole of official terrestrial magnetism. The number and position of the observatories-Sitka, Cheltenham, Tucson, Vieques (Porto Rico), and Honolulu-is determined primarily by survey considerations. The same idea prevailed to a certain extent in India, but the oldest magnetic observatory, Alibag-regarded as the continuation of Colaba, Bombay-represents a more usual form of development.

In most countries terrestrial magnetism has not been an independent plant, but from the point of view of astronomers and meteorologists has been a parasitical growth on astronomy or meteorology. Greenwich may perhaps be regarded as an example of this. At present most magnetic observatories are under the meteorological service of the country, and one of the two international associations concerned with the subject is the Magnetic Commission of the International Meteorological Committee. It is under its auspices that a selection of international quiet and disturbed days is made at De Bilt, Netherlands. The other international association, the Section of Terrestrial Magnetism and Electricity of the International

NO. 2964, vOL. I I 8] 